\title{
大腿骨䅡部骨折に対する骨接合術の検討
}

\author{
砥上若 菜* 橋 本 伸 朗* 福 元 哲 也* \\ 前田智* 中馬東 彦* 野村一俊*
}

\section{Evaluation of Osteosynthesis for Femoral Neck Fractures}

\begin{abstract}
Wakana Togami*, Noburo Hashimoto*, Tetsuya Fukumoto*,
\end{abstract} Satoshi Maeda*, Haruhiko Chuma*, and Kazutoshi Nomura*

【目的】過去 5 年間における，当院での大腿骨頝部骨折に対する骨接合術の術後成績を検討した. 【対 象】症例は術後 6 ヶ月以上追跡可能であった 65 例 66 股であった. 術式では CHS : 30 股, CHS+screw : 9 股, Twin Hook ( $\mathrm{T}$ 群) : 10 股, Hansson pin ( $\mathrm{H}$ 群) : 17 股であり, 骨折型では Garden I 型 : 13 股, II 型： 41 股, III型 : 12 股であった.【方法】手術時間, 骨癒合・合併症の有無, GAI (Garden alignment index), 骨折型と合併症との関係を検討した。【結果】手術時間は H 群が平均 24 分と最も短時間 であった。骨癒合例と合併症例の GAI には明らかな有意差は認められなかった。合併症は Garden II 型 の中でも後捻 type に 16\%， III 型に 45.5\% 認められた. T 群， H 群はテクニカルエラーによる合併症が 主であった。【結論】大腿骨䭘部骨折の骨接合術では, レ線軸射像を含む骨折型の把握と手術手技を十分 に習熟する事が重要である.

【Purpose】 We evaluated the results of osteosynthesis of femoral neck fractures in the past five years. 【Object】 We treated 66 cases which we could follow-up for more than postoperative six months. Internal fixation procedures were performed using $30 \mathrm{CHS}$, nine CHS+screws, 10 Twin Hooks, and 17 Hansson pins. According to the modified Garden's classification, there were 13 stage I, 41 stage II, 12 stage III. 【Method】 Clinical evaluation was based on the operation time, fracture union rate, complications, GAI and bone fracture type, and relations with the complication. 【Result】 The Hansson pin group had the shortest operation time of 42 minutes on average. Clear significant differences were not seen in GAI between bone union cases and complication cases. As for complications, it was accepted 16\% in Garden stage II (retroversion type) and $45.5 \%$ in Garden stage III. For the Twin Hook group and Hansson pin group, complication were mainly due to technical errors. 【Conclusion】 It is very important to have sufficient understanding of bone fracture stages including axial view of X-rays and manual operation skills.

Key words : femoral neck fractures（大腿骨頚部骨折）， osteosynthesis（骨接合術），Garden's classification (Garden 分類)

は じめに

大腿骨頚部骨折に対する骨接合術には様々な内固定 材料が用いられている. 今回, 我々は当院にて主に使 用された 4 つの内固定材料 (CHS, CHS + screw, Twin Hook, Hansson pin) について治療成績を検 討したので, 若干の文献的考察を加えて報告する.

\section{対象及び方法}

2002 年 5 月から 2007 年 5 月までの 5 年間に CHS, CHS+screw, Twin Hook, Hansson pinのいずれ かを用いて骨接合術を行った 120 例 121 股の内，死亡 例や連絡がつかなかつた症例を除き, 術後 6 ケ月以上 追跡可能であった 66 例 67 股を対象とした.

内固定材料別の症例数は CHS : 30 股, CHS + screw :

\footnotetext{
* 国立病院機構熊本医療センター整形外科 Department of Orthopaedic Surgery, National Hospital Organization Kumamoto Medical Center, Kumamoto, Japan
} 
9 股, Twin Hook : 10 股, Hansson pin : 17 股であつ た.

骨折型の分類には従来の Garden 分類 ${ }^{1)}$ を使用し, 更に II 型をレ線軸射像において後捻の有無で独自に分 類し, 後捻の無いものを II - $\mathrm{a}$ 型, 後捻のあるものを II -b 型とした．骨折型別の症例数は I 型 : 13 股， II $\mathrm{a}$ 型 $: 12$ 股, $\mathrm{II}-\mathrm{b}$ 型 : 29 股, $\mathrm{II}$ 型 : 12 股, IV 型 : 0 股であった。

内固定材料は，2006 年 7 月まで CHS+screw 及び Key less type のCHS を使用し，その後，骨頭回旋 防止目的 ${ }^{2)}$ に 2006 年 1 月から Twin Hook の使用を 開始した。また，2006 年 7 月より現在に至るまで主 にHansson pin を使用し手術を施行している（図 1). 術中整復は, Garden I 型・II -a 型で牽引台上で動 きの無いものはそのまま固定し, Garden II -b 型・III 型は整復して固定した.

執刀は, 経験年数の違う 12 名の医師が行つた.

後療法は，骨接合部の安定性が良かつた症例は，術
翌日より安静度・荷重制限なしとした。

調査項目は，手術時間，骨癒合・合併症の有無，骨 癒合例と合併症例における両群の GAI（Garden alignment index ${ }^{1)}$ ) の比較，骨折型と合併症の関係 であった

$$
\text { 結果 }
$$

手術時間は平均 42.1 分であり, 内 Hansson pin が 平均 24 分と最も短時間であった.

術後合併症は, 全症例中 cut out : 5 股, 骨癒合不 全 : 3 股, 骨頭壊死 : 2 股, 感染 : 1 股が認められた. 内固定材料別には，CHS では cut out：1股，骨癒合 不全 : 2 股, 骨頭壊死 $: 1$ 股, CHS + screw では感染 : 1 股, Twin Hook では cut out : 2 股, Hansson pin では cut out : 1 股, 骨癒合不全 : 1 股, 骨頭壊死 $: 1$ 股であった。尚，骨癒合率は全ての内固定材料で $80 \%$ 以上であった（表 1 ).

骨折型別の合併症の割合に関しては, Garden I 型

\section{CHS+screw}

CHS

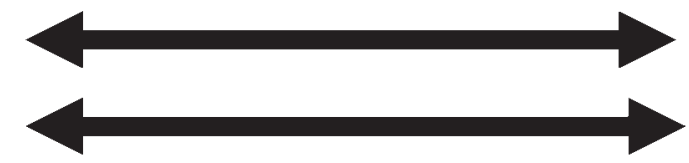

\section{Twin Hook}

Hansson pin

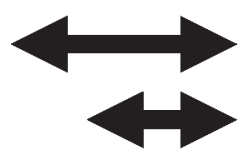

$\begin{array}{llllll}2002 & 2003 & 2004 & 2005 & 2006 & 2007\end{array}$

図 1 年代別 内固定材料

表 1 合併症例数及び骨癒合率

\begin{tabular}{|c|c|c|c|c|c|c|}
\hline & $\begin{array}{l}\text { Follow } \\
\text { 可能例 }\end{array}$ & cut out & 骨癒合不全 & 骨頭壊死 & 感染 & 骨癒合 \\
\hline CHS & 30 & $\begin{array}{c}1 \\
(3.3 \%)\end{array}$ & $\begin{array}{c}2 \\
(6.7 \%)\end{array}$ & $\begin{array}{c}1 \\
(3.3 \%)\end{array}$ & 0 & $\begin{array}{c}26 \\
(86.7 \%)\end{array}$ \\
\hline CHS+screw & 9 & 0 & 0 & 0 & $\begin{array}{c}1 \\
(11.1 \%) \\
\end{array}$ & $\begin{array}{c}8 \\
(88.9 \%) \\
\end{array}$ \\
\hline Twin Hook & 10 & $\begin{array}{c}2 \\
(20 \%) \\
\end{array}$ & 0 & 0 & 0 & $\begin{array}{c}8 \\
(80 \%) \\
\end{array}$ \\
\hline Hansson pin & 17 & $\begin{array}{c}1 \\
(5.9 \%) \\
\end{array}$ & $\begin{array}{c}1 \\
(5.9 \%) \\
\end{array}$ & $\begin{array}{c}1 \\
(5.9 \%) \\
\end{array}$ & 0 & $\begin{array}{c}14 \\
(82.3 \%)\end{array}$ \\
\hline total & 66 & $\begin{array}{c}5 \\
(7.5 \%)\end{array}$ & $\begin{array}{c}3 \\
(4.5 \%)\end{array}$ & $\begin{array}{c}2 \\
(3.0 \%)\end{array}$ & $\begin{array}{c}1 \\
(1.5 \%)\end{array}$ & $\begin{array}{c}56 \\
(84.8 \%)\end{array}$ \\
\hline
\end{tabular}


及び II -a 型では 0 \% であったが，Garden II -b 型は 16\% (CHS : 1 股, Hansson pin : 2 股), Garden III 型では 45.5\% (CHS : 3 股，Twin Hook : 2 股）で あった.

GAI は合併症例では軸射像にて若干の低值を認め たが，明らかな差は認めなかった（表 2).

表 2 GAI (Garden alignment index)

\begin{tabular}{c|c|c|c}
\hline \hline \multirow{2}{*}{} & \multicolumn{2}{|c|}{ 骨癒合例 } & 合併症例 \\
\cline { 2 - 4 } & $\begin{array}{c}\text { 術直後 } \\
(\text { 平均 })\end{array}$ & 骨癒合時 & $\begin{array}{c}\text { 術直後 } \\
\text { (平均 })\end{array}$ \\
\hline \multirow{2}{*}{ 正面 } & $157 \sim 177.5^{\circ}$ & $152.2 \sim 178.5^{\circ}$ & $151 \sim 187^{\circ}$ \\
& $\left(168.2^{\circ}\right)$ & $\left(165.9^{\circ}\right)$ & $\left(167.5^{\circ}\right)$ \\
\hline \multirow{2}{*}{ 軸位 } & $158.5 \sim 187^{\circ}$ & $157.3 \sim 181.5^{\circ}$ & $158 \sim 178.6^{\circ}$ \\
& $\left(173.5^{\circ}\right)$ & $\left(172.8^{\circ}\right)$ & $\left(170.3^{\circ}\right)$ \\
\hline
\end{tabular}

表 3 大腿骨頚部内側骨折に対する骨接合術後の合併症

\begin{tabular}{c|c|c} 
表 3 大腿骨䅡部内側骨折に対する骨接合術後の合併症 \\
\hline \hline Garden 分類 & I 型 $\quad$ II 型 & III型 $\quad$ IV型 \\
\hline 骨癒合率 & $85 \% \sim 100 \%$ & $60 \% \sim 96 \%$ \\
\hline 骨頭壊死 & $4 \% \sim 21 \%$ & $46 \% \sim 57 \%$ \\
\hline
\end{tabular}

a

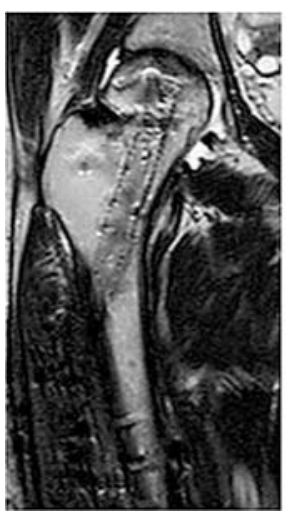

受傷時の血流障害

$\mathrm{b}$

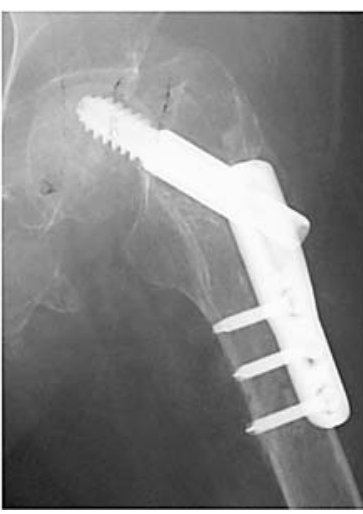

整復不良
考

察

大腿骨頚部/転子部骨折診療ガイドライン で で報告 されている大腿骨頚部骨折に対する骨接合術後の合併 症の割合を, Garden 分類別に表 3 に示した，当院で の骨癒合率は，Garden I 型と II -a 型は $100 \%$ であり， II -a 型は $84.5 \%$ ， III 型は $55.5 \%$ であった，骨頭壊死 は II -b 型は $3.4 \% ，$ III 型は $8.3 \%$ であり，文献上の報 告より低值であった。しかし，これは，術後経過観察 可能であった症例が $55.4 \%$ と少数であったこと, 経 過観察期間が短いことなどが影響していると考えられ る.

次に, 内固定材料別の合併症発生の原因を検討した. CHS では，骨頭壊死（図 2-a）, 術後の cut out（図 2b), lag screw の back out (図 2-c), plateの脱転 （図 2-d）が認められた. Twin Hook の合併症は, ど ちらも Garden III型に認め, 術後 cut out を来たした. 侵入位置の不良（図 3-a）, ツインフックの長さ不足 （図 3-b）などの technical error が原因と考えられた. Hansson pin の合併症は，全て Garden II -b 型であ り，偽関節（図 4-a)，cut out（図 4-b)，骨頭壊死 （図 4-c）を認めた。

図 2 CHS 合併症例

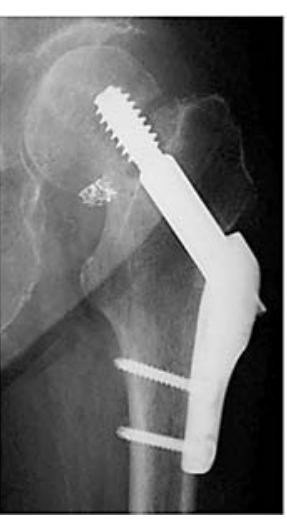

key less type を使用 d

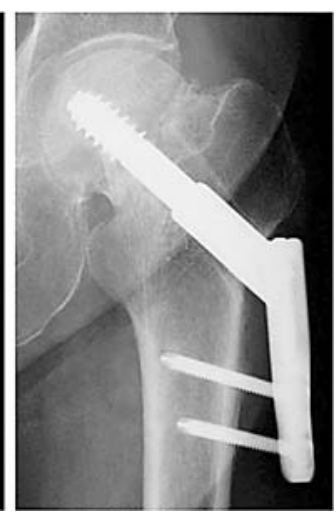

原因不明
a) Garden III型：受傷時の血流障害
b) Garden III型：整復不良
c) Garden III型 : Key less type を使用
d) Garden II - b 型：原因不明 
a
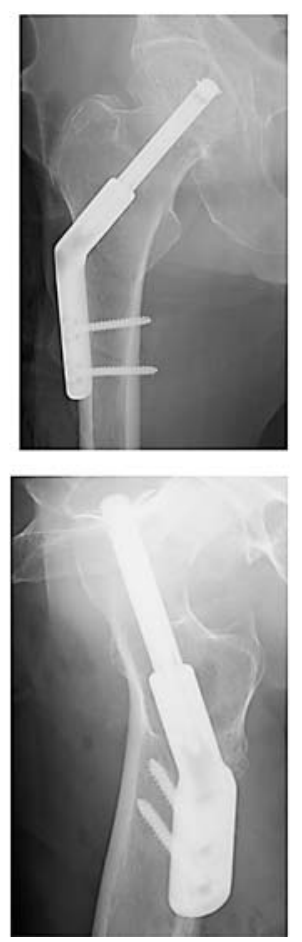

術直後
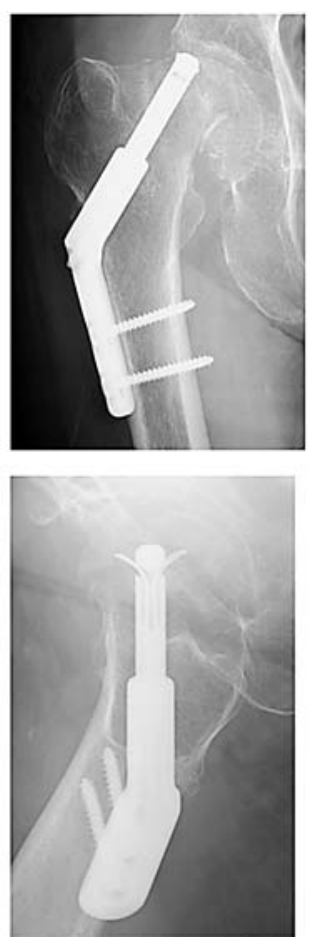

術後 2 ヶ月

侵入位置不良

図 3 Twin Hook 合併症例
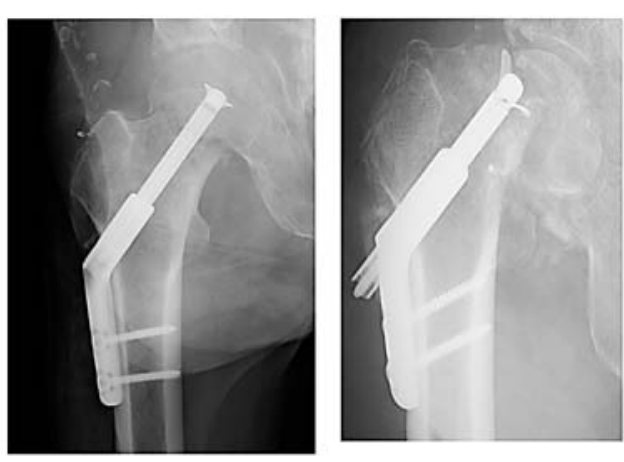

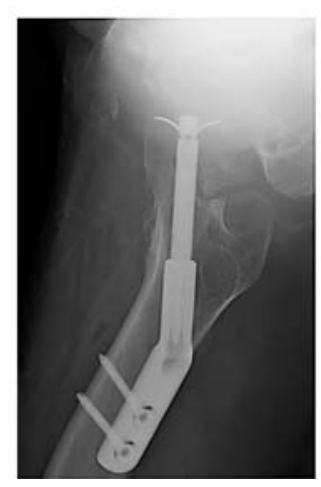

術直後

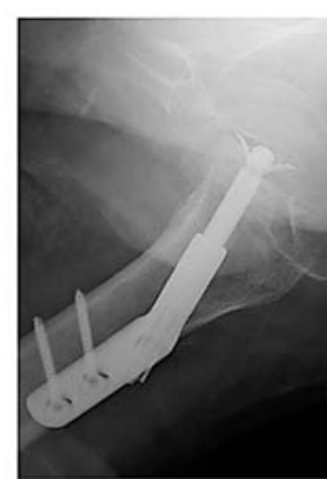

術後 3 ケ月

ピンの長さ不足

a) Garden III 型 : 侵入位置不良

b) Garden III型 : ピンの長さ不足

内固定材料別の利点・欠点 2335 (5) を表 4 にまとめた. 当院での合併症では, key less type の CHS は回 旋保持力が悪く, back outを来たした症例が認めら れた. Twin Hook ・ Hansson pin の回旋保持力は優 れている. しかし, 術者のテクニカルエラーが合併症 の原因となった症例が多かったため, 手術手技に十分 に習熟する必要があると思われた.

現在，大腿骨頚部骨折の治療法の選択には Garden 分類が主に用いられている. しかし当院での症例にお いて， II 型の中でも特にレ線軸射像での後捻の有無に よって術後合併症の発生率は異なっていた，骨接合術 の術後合併症発生率を低下させるには, 特に II 型にお いて骨折型をレ線正面像だけでなく, 軸射像も十分検 討して治療法を選択する必要があると思われた.
ま と め

大腿骨頚部骨折の術後 6 ケ月以上追跡可能であった 65 例 66 股の術後成績について検討した.

合併症発生率は Garden I 型・II -a 型は $0 \%$ であつ たが，Garden II -b 型は 16\%，Garden III 型は 45.5\% に認められた.

Twin Hook, Hansson pin はテクニカルエラーに よる合併症が主であった。

大腿骨頚部骨折の骨接合術では，レ線軸射像を含む 骨折型の把握と手術手技を十分に習熟する事が重要で ある。 
a
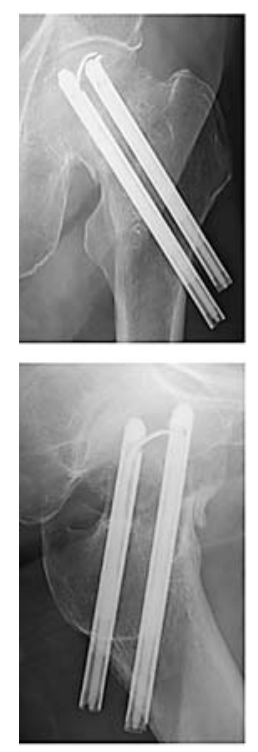

術後 3 ケ月半 整復不良 b
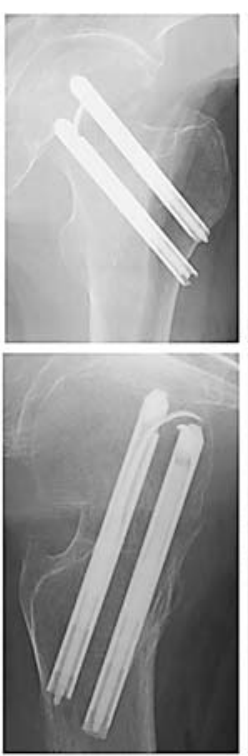

術直後
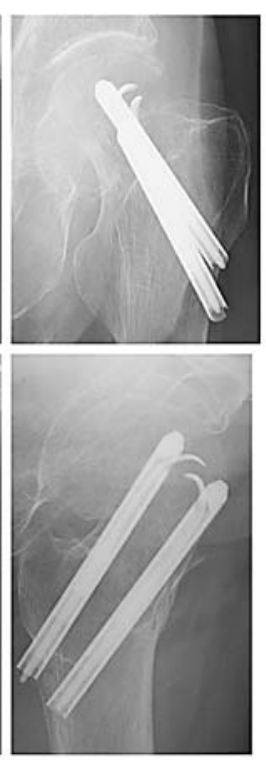

術後 10 日

ピン刺入位置不良

c
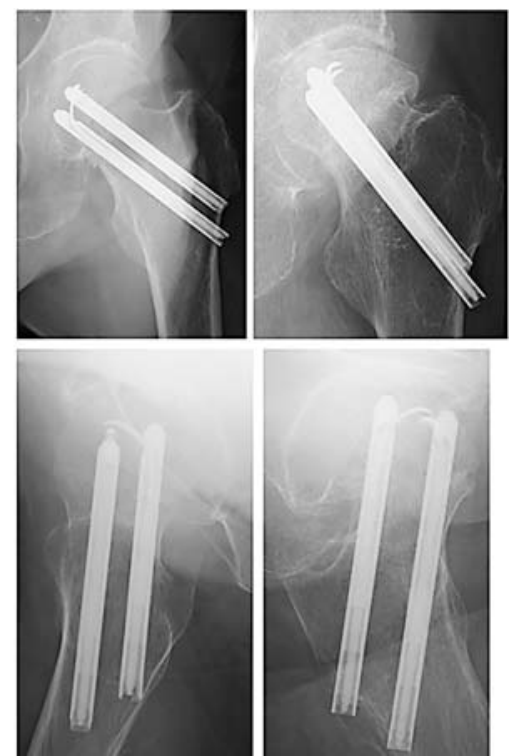

術直後

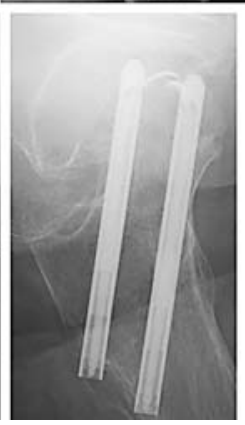

術後 9 ヶ月

図 4 Hansson pin 合併症例

a) Garden II - b 型 : 整復不良

b) Garden II - b 型：ピン刺入位置不良

c) Garden II - b 型：原因不明

表 4 内固定材料別の利点 - 欠点

\begin{tabular}{|c|c|c|c|c|c|}
\hline & \multicolumn{3}{|c|}{ 手術時 } & \multicolumn{2}{|c|}{ 術 後 } \\
\hline & 手術時間 & 回旋防止 & $\begin{array}{l}\text { ピン侵入位 } \\
\text { 置の許容度 }\end{array}$ & $\begin{array}{l}\text { 回旋 } \\
\text { 保持力 }\end{array}$ & $\begin{array}{l}\text { 骨頭血 } \\
\text { 流温存 }\end{array}$ \\
\hline CHS & 0 & $\triangle$ & 0 & $\triangle$ & O? \\
\hline CHS+ screw & $\triangle$ & $\triangle$ & $\mathrm{O}$ & $\triangle$ & O? \\
\hline Twin Hook & 0 & (a) & $\triangle$ & 0 & 0 \\
\hline Hansson pin & (0) & (0) & $\triangle$ & 0 & 0 \\
\hline
\end{tabular}

参 考 文 献

1) Garden, R. S.: Low-angle fixation in fractures of the femoral neck. J. Bone Joint Surg., $43: 647-663$, 1961.

2) 生田拓也：大腿骨頚部内側骨折に対する骨接合術. Orthopedics, 16(12) : 34-40, 2003.

3）最上 敦彦, 他 : Hansson Twin Hook System を使 用した大腿骨頸部骨折の治療経験. Hip Joint, 33 : 518-522, 2007.
4）日本整形外科学会診療ガイドライン委員会, 他 : 大腿 骨頚部/転子部骨折診療ガイドライン, pp.90-91. 東京, 南江堂, 2005 .

5）野々宮廣章，他：大腿骨頚部内側骨折に対するハンソ ンピンシステムによる治療経験。骨折, $23: 389-393$, 2001.

6）野々宮廣章：高齢者大腿骨澒部（内側）骨折に対する ハンソンピン固定術. Orthopedics, 19(5) : 21-29, 2006. 